\title{
Reconstruction of specific mass balance for glaciers in Western Himalaya using seasonal sensitivity characteristic(s)
}

\author{
Vinay Kumar Gaddam ${ }^{1, *}$, Anil V Kulkarni ${ }^{2}$ and Anil Kumar Gupta ${ }^{3}$ \\ ${ }^{1}$ Cryosphere Science Division, National Center for Antarctica and Ocean Research, Goa, India. \\ ${ }^{2}$ Divecha Center for Climate Change, CAOS, Indian Institute of Science, Bangalore 560 012, India. \\ ${ }^{3}$ Department of Civil Engineering, Dr. Ambedkar Institute of Technology, Visvesvaraya Technological \\ University-RC, Bangalore, India. \\ *Corresponding author.e-mail: Gaddam_vinay@ymail.com; vinay@ncaor.gov.in
}

MS received 9 September 2016; revised 10 February 2017; accepted 12 February 2017;

published online 12 June 2017

Seasonal sensitivity characteristics (SSCs) were developed for Naradu, Shaune Garang, Gor Garang and Gara glaciers, Western Himalaya to quantify the changes in mean specific mass balance using monthly temperature and precipitation perturbations. The temperature sensitivities were observed high during summer (April-October) and precipitation sensitivities during winter months (NovemberMarch), respectively. The reconstructed mass balance correlates well with the field and remote sensing measurements, available between 1980 and 2014. Further, SSCs were used with the monthly mean temperatures and precipitation estimates of ERA 20CM ensemble climate reanalysis datasets to reconstruct the specific mass balance for a period of 110 years, between 1900 and 2010. Mass balance estimates suggest that the Shaune Garang, Gor-Garang and Gara glaciers have experienced both positive and negative mass balance, whereas the Naradu glacier has experienced only negative mass balance since 1900 AD. Further, a cumulative loss of $-133 \pm 21.5$ m.w.e was estimated for four glaciers during the observation period. This study is the first record from Indian Himalaya in evaluating the mass balance characteristics over a century scale.

Keywords. Specific mass balance; seasonal sensitivity characteristic; Baspa basin; Western Himalaya.

\section{Introduction}

Himalayan glaciers play a significant role in providing the melt runoff to $\sim 1.3$ billion people for domestic and industrial applications (Rathore et al. 2009; Immerzeel et al. 2010; Bolch et al. 2012; Kulkarni 2014). Due to their rapid wastage and huge mass turnover, these glaciers are highly sensitive to the climate change (Adhikari and Hybrechts 2009; Maurer et al. 2016; Zhao et al. 2016). At present, they are under threat due to ongoing rise in temperatures, rapid industrialization and other anthropogenic factors (IPCC 2014; Kulkarni et al. 2007, 2013; Immerzeel et al. 2010; Gaddam et al. 2016). Understanding the glacier response/sensitivity to climate change is therefore necessary to assess evolution over long-term and possible changes in water resources at regional level (Kulkarni 2014). Glacier's sensitivity is determined by the factors such as glacier shape/size, hypsometry, bed topography and mass balance (Adhikari and Hybrechts 2009). Out of these, mass 
balance is a crucial parameter which governs the extent of a glacier, by forming a vital link with the changing climate (Paterson 1998; Oerlemans 2001). Several mass balance investigations were carried in Indian Himalaya, and suggests that the glaciers (except Karakoram) have experienced negative mass balance (Bolch et al. 2012; Gardelle et al. 2013; Vincent et al. 2013; Azam et al. 2014; Gaddam et al. 2016; Pratap et al. 2016). However, these studies are based on the mass balance observations of few glaciers and for short durations starting after 1970s. Long-term mass balance characteristics of Himalayan glaciers are still unknown.

Glacier mass balance studies in Indian Himalaya have many limitations like (a) field-based investigations are rare due to harsh weather, rugged topography and limitations in providing the high altitude logistics. As a result, field mass balance exists only for 12 glaciers (Kulkarni and Karyakarte 2014; Gaddam et al. 2016). (b) Remote sensing (AAR/ELA and geodetic) studies are limited to the availability of satellite data and for very short period (Kulkarni et al. 2004; Gardelle et al. 2013; Gaddam et al. 2016), and (c) limitation exists in regression-based analysis, since it includes more number of predictands, differ from glacier to glacier for a given climate setting (Rabatel et al. 2013). Therefore, in order to estimate the long term (century scale) mass balance of individual glaciers, Oerlemans and Reichert (2000) have defined a method based on seasonal sensitivity characteristic (SSC: $2 \times 12$ matrix). This gives the dependence of specific mass balance on monthly perturbations in temperature and precipitation. Therefore, in the present study, the SSC method is adopted to evaluate the long term mass balance of four glaciers located in Western Himalaya (figure 1). The SSCs are developed using meteorological data obtained from Rakcham Observatory (3050 m.a.s.l) and a temperature index melt model, which were further forced with ERA 20CM ensemble climate reanalysis datasets available from European Centre for Medium-range Weather Forecasting center (ECMWF) to reconstruct the glacier's specific mass balance for a period of 110 years between 1900 and 2010, respectively.

\section{Study area}

Baspa basin is a fifth order basin of Sutlej river, Western Himalaya and consists of 89 glaciers covering a geographical area of $238.65 \mathrm{~km}^{2}$ (Raina and Srivastava 2009). Out of these glaciers, three glaciers namely Naradu $\left(3.7 \mathrm{~km}^{2}\right)$, Shaune Garang $\left(6.0 \mathrm{~km}^{2}\right)$, Gor-Garang $\left(3.8 \mathrm{~km}^{2}\right)$ along with Gara glacier, located in Gara Khad basin (adjacent to Gor-Garang glacier, Baspa valley) were selected for the study. These four glaciers were considered for the study because of the availability of long term field mass balance measurements (GSI 1992; Sangewar and Siddiqui 2007; Koul and Ganjoo 2010). The altitude of these glaciers varies between 4400 and $5800 \mathrm{~m}$, with the equilibrium line altitudes (ELAs) at 5100-5200 m.a.s.l (Koul and Ganjoo 2010; Gaddam et al. 2016). Glaciers in this basin receive precipitation from both the westerlies and monsoon (Kulkarni et al. 2004). The discharge of Baspa River starts to rise in April/May due to snow melt and reaches its maximum in July/August with monsoonal rainfall (Wulf et al. 2010).

\section{Methodology and data}

Mass balance is a difference between amount of accumulation of snow and then ablation of snow/ ice. Accumulation of snow is estimated using precipitation and ablation by temperature or energy balance parameters. Energy balance approach needs several parameters such as radiation fluxes, albedo, cloud cover, latent heat, etc., whereas temperature index relies solely on air temperature (Hock 2005). Due to lack of energy balance components in Himalaya, temperature is generally used to assess the ablation (Kulkarni et al. 2002; Hock 2005). Many hydrological and mass balance studies being carried in the Himalaya have utilized the temperature index models frequently at various spatio-temporal scales, because of the easy interpolation, computation simplicity and good forecasting possibilities of air temperature (Hock 2003, 2005; Pellicciotti et al. 2008; Shea et al. 2009; Carenzo et al. 2016; Zhao et al. 2016). Hence, in this study the temperature index approach is considered to estimate the mass balance.

\subsection{Estimation of mass balance between 1985-1986 and 2013-2014}

The daily maximum and minimum temperatures, snow water equivalent and rainfall obtained from Rakcham Meteorological Observatory, located at $3050 \mathrm{~m}$ (figure 1) are used in this study for mass balance estimation. Daily melt was computed 


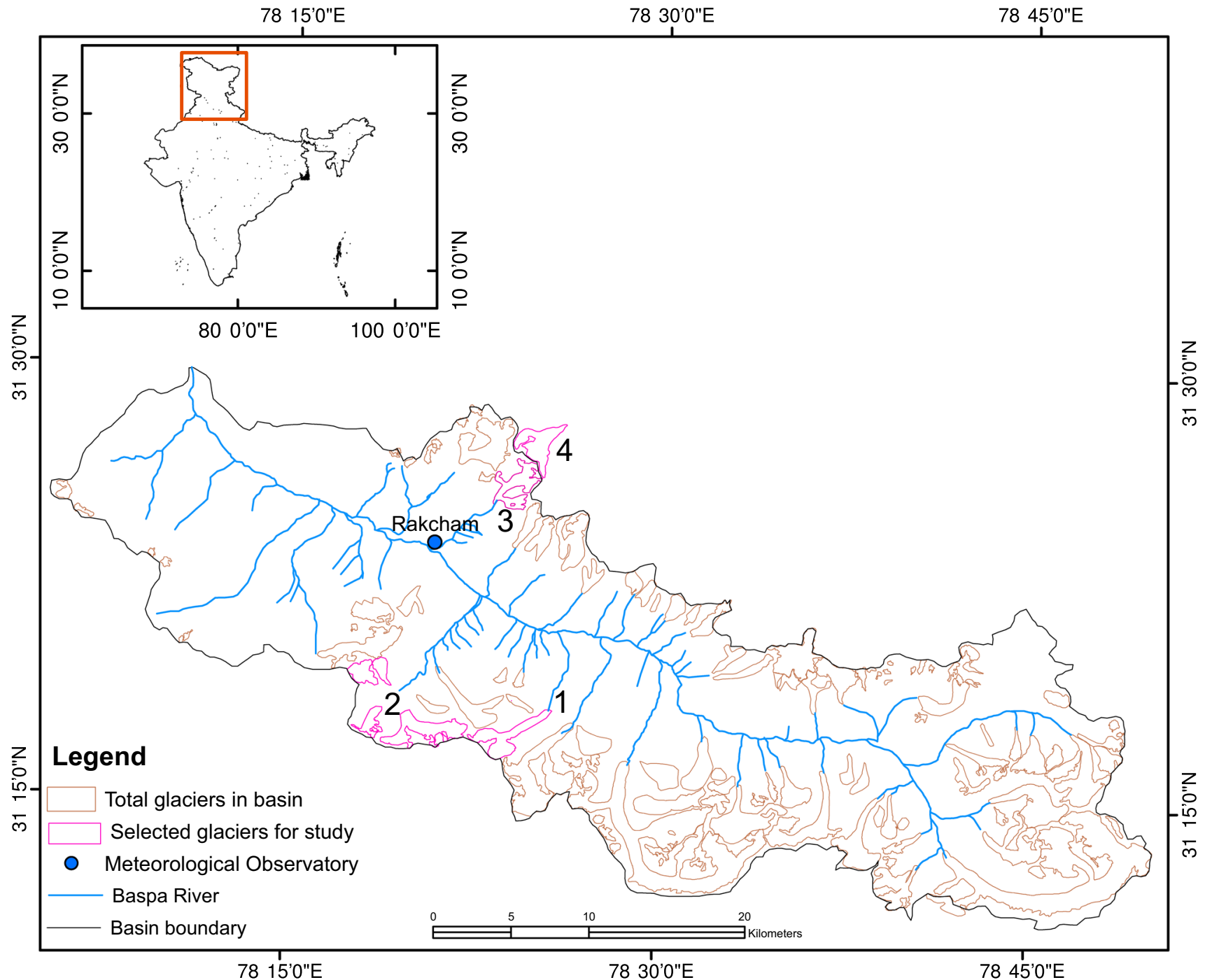

Figure 1. Geographical location of selected glaciers (1. Naradu, 2. Shaune Garang, 3. Gor-Garang and 4. Gara) and meteorological observatory in Baspa valley, Himachal Pradesh, India.

Table 1. Seasonal variations and melt factors (Kulkarni et al. 2002) considered for the study.

\begin{tabular}{lll}
\hline Season & \multicolumn{1}{c}{ Period } & $\begin{array}{l}\text { Melt factors } \\
\left(\mathrm{cm}^{\circ} \mathrm{C}^{-1} \mathrm{~d}^{-1}\right)\end{array}$ \\
\hline Summer & March 21-July 10 & 0.5 \\
Autumn & September 11-November 30 & 0.6 \\
Monsoon & July 11-September 10 & 0.55 \\
Winter & December 1-March 20 & 0.5 \\
\hline
\end{tabular}

using the temperature index melt model, which relates the ice/snow melt (M-mm) with the sum of positive air temperatures of each time interval $\left(T^{+}\right)$, during ' $n$ ' intervals of time $(\Delta t)$. The factor of proportionality is the melt factor, expressed in $\mathrm{mm} \mathrm{d}^{-1} \mathrm{k}^{-1}$ for $\Delta t$ (given in days) and temperature in ${ }^{\circ} \mathrm{C}$ (equation 1; Hock 2003).

$$
\sum_{i=1}^{n} M=\text { Melt factor } \sum_{i=1}^{n} T^{+} \Delta t \text {. }
$$

Temperatures were adjusted using a lapse rate of $7.14^{\circ} \mathrm{C} / \mathrm{km}$ (Singh and Bengtsson 2004) for various altitudes and then melt factors (table 1 ) were used to calculate the ablation. Different melt factors were considered since they vary from day to day according to the seasonal variations, high altitude topography and steep slopes (Kulkarni et al. 2002). Accumulation is calculated using precipitation with a gradient of $\sim 0.12 \mathrm{~m} / \mathrm{km}$ 

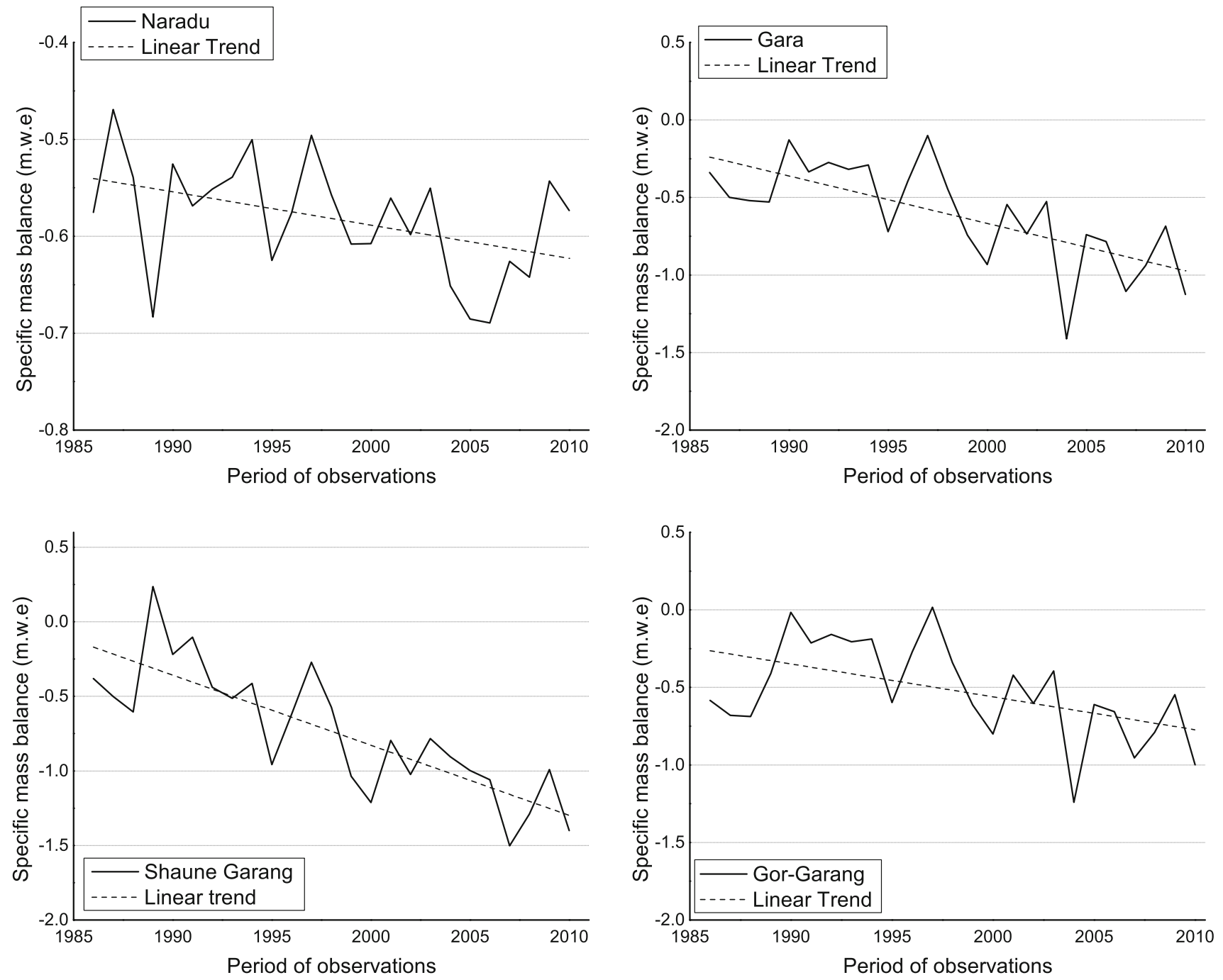

Figure 2. Specific mass balance (m.w.e) of Naradu, Gara, Shaune Garang and Gor-Garang glaciers derived using Rakcham meteorological data, for a period of 30 hydrological years between 1985-1986 and 2013-2014.

(Wulf et al. 2010). Further, mass balance is estimated by integrating the melt $(\mathrm{m})$ and accumulation $(\mathrm{m})$ over a period of 30 years, between 1985 and 2015 (figure 2).

\subsection{Estimation of SSC and mass balance using ERA20CM datasets}

$\operatorname{SSC}\left(C_{T, k}, C_{p, k}\right)$ is a $2 \times 12$ matrix, which contains the sensitivity of $B_{m}$ (specific mass balance) to monthly perturbations in temperature $(T)$ and precipitation $(P)$ (equations 2,3 ). These can be calculated with a simple or complex mass balance model (Oerlemans and Reichert 2000). In this study, $C_{T, k}$ and $C_{p, k}$ (24 values) were obtained by computing $B_{m}$ from a run of temperature index melt model. First, the observed balance profile is simulated by adjusting the climatological input (within the range of uncertainty). The mean observed balance over the time span of measurements is not zero, and to provide a reference state $\left(B_{m}=0\right)$ the annual mean air temperature was adjusted within $\pm 2 \mathrm{~K}$ (de Wildt et al. 2003; Hersbach et al. 2015). During this process, the basic assumption suggested by Oerlemans and Reichert (2000) is considered, i.e., SSC works only when the perturbations are small (the abrupt values were discarded by considering the temperature and precipitation anomalies, which exceed more than $2 \mathrm{~K}$ and $40 \%$ ). Then $C_{T, k}$ and $C_{p, k}$ were determined for all four glaciers individually by running the model with the monthly temperature and perturbations of $\pm 1 \mathrm{~K}$ and $\pm 10 \%$ (between 1985 and 2014), respectively. 


$$
\begin{aligned}
C_{T, k} & =\frac{\partial B_{m}}{\partial T_{k}} \\
& =\frac{B_{m}\left(T_{\text {ref }, k}+\Delta T\right)-B_{m}\left(T_{\text {ref }, k}-\Delta T\right)}{2 \Delta T} \\
C_{p, k} & =\frac{\partial B_{m}}{\partial P_{k}} \\
& =\frac{B_{m}\left(P_{\text {ref }, k}+\Delta P\right)-B_{m}\left(P_{\text {ref }, k}-\Delta P\right)}{2 \Delta P}
\end{aligned}
$$

where $k$ is the month and $\Delta T$ and $\Delta P$ are $1 \mathrm{~K}$ and $10 \%$, respectively.

$$
\begin{aligned}
B_{m}= & B_{m, \text { ref }}+\sum_{k=1}^{12}\left[C_{T, k}\left(T_{k}-T_{\text {ref }, k}\right)\right. \\
& \left.+C_{p, k}\left(p k-P_{\text {ref }, k}\right) / P_{\text {ref }, k}\right]
\end{aligned}
$$

where $B_{m \text {, ref }}$ is the mean specific mass balance when $T$ and $P$ are not perturbed.

With the $C_{T, k}$ and $C_{p, k}$, long term specific mass balance $\left(B_{m}\right)$ can be reconstructed using monthly perturbation in $T$ and $P$ (equation 4 ), either from instrumental records or General Circulation Model (GCM)'s data (Oerlemans and Reichert 2000; de Wildt et al. 2003). However, the instrumental records (AWS data) in Indian Himalaya are only available from 1960 onwards (BBMB 2014). Therefore, ERA-20 CM climate reanalysis gridded datasets available with $0.125^{\circ}$ spatial resolution were considered for mass balance reconstruction for a period of 110 years between 1900 and 2010 .

\subsection{Uncertainty estimation}

The root mean square error (RMSE) in mass balance estimates are calculated using the formula, given by Chai and Draxler (2014) (equation 5).

$$
\mathrm{RMSE}=\sqrt{\frac{1}{n} \sum_{i=1}^{n} e_{i}^{2}}
$$

where $n$ is the number of samples of model $e_{i}(i=$ $1,2, \ldots, n)$.

\section{Results and discussion}

\subsection{Mass balance observations and uncertainties during 1985-2010}

Annual specific mass balances are calculated for Naradu, Gara, Shaune and Gor-Garang glaciers for a period of 30 hydrological years, between 19851986 and 2013-2014 (figure 2). The observations suggest that all the glaciers, except Shaune Garang glacier have experienced negative mass balance in this period. Shaune Garang has showed a positive mass balance of 0.23 m.w.e, during the 1988-1989 hydrological year. Despite this, the linear trends for four glaciers indicate an increase in mass loss (figure 2). This is due to rapid warming temperatures and precipitation deficiency in this basin (figure 6 ; Gaddam et al. 2016). The mass loss of all the four glaciers during the hydrological years 1985-1986 to 1994-1995 ( $\approx-0.45$ m.w.e.a $\left.{ }^{-1}\right)$ was less compared to the mass loss $\left(\approx-0.8\right.$ m.w.e. $\left.a^{-1}\right)$, after 1995 1996. Similar results were observed by the studies being carried in Western Himalaya (Kulkarni 2014; Gaddam et al. 2016; Zhao et al. 2016).

To analyse the uncertainties of temperature index model, estimated values were compared with the field mass balance measurements of Naradu and Shaune Garang glaciers, available between 1985 and 2014 (figure 3). Gara and Gor-Garang glaciers were not chosen for the uncertainty analysis due to lack of field observations during the same period (1985-2014). The analysis suggests that the model is able to calculate the specific mass balance with higher accuracy. The uncertainties (root mean square difference) in deriving the mass balance for Naradu and Shaune Garang are \pm 0.23 and \pm 0.33 m.w.e, whereas the root mean square errors for Gara and Gor-Garang are \pm 0.28 and \pm 0.24 m.w.e, respectively.

\subsection{Seasonal sensitivity characteristics (SSCs)}

SSCs of the four glaciers were obtained individually (figure 4 ), by imposing temperature $(T)$ and precipitation $(P)$ perturbations of $1 \mathrm{~K}$ and $10 \%$ (separately for each month). Each time, the model is run from 1985 to 2014 and the sensitivities are then averaged over the years. The temperature is perturbed at unperturbed precipitation, and vice versa to remove the natural correlations of $T$ and $P$ (Oerlemans and Reichert 2000). The SSCs of four glaciers (figure 4) and reconstructed mass balance of Shaune Garang glacier (figure 5a and b; developed using temperature and precipitation perturbation individually) indicates that the temperature is a major factor, than the precipitation which highly influences the glacier's sensitivity (Adhikari and Hybrechts 2009; Engelhardt et al. 2015; Huss and Fischer 2016). Also, SSCs indicate the phenomena of both the westerlies (November-March) and monsoon precipitation (April-October). In the accumulation 

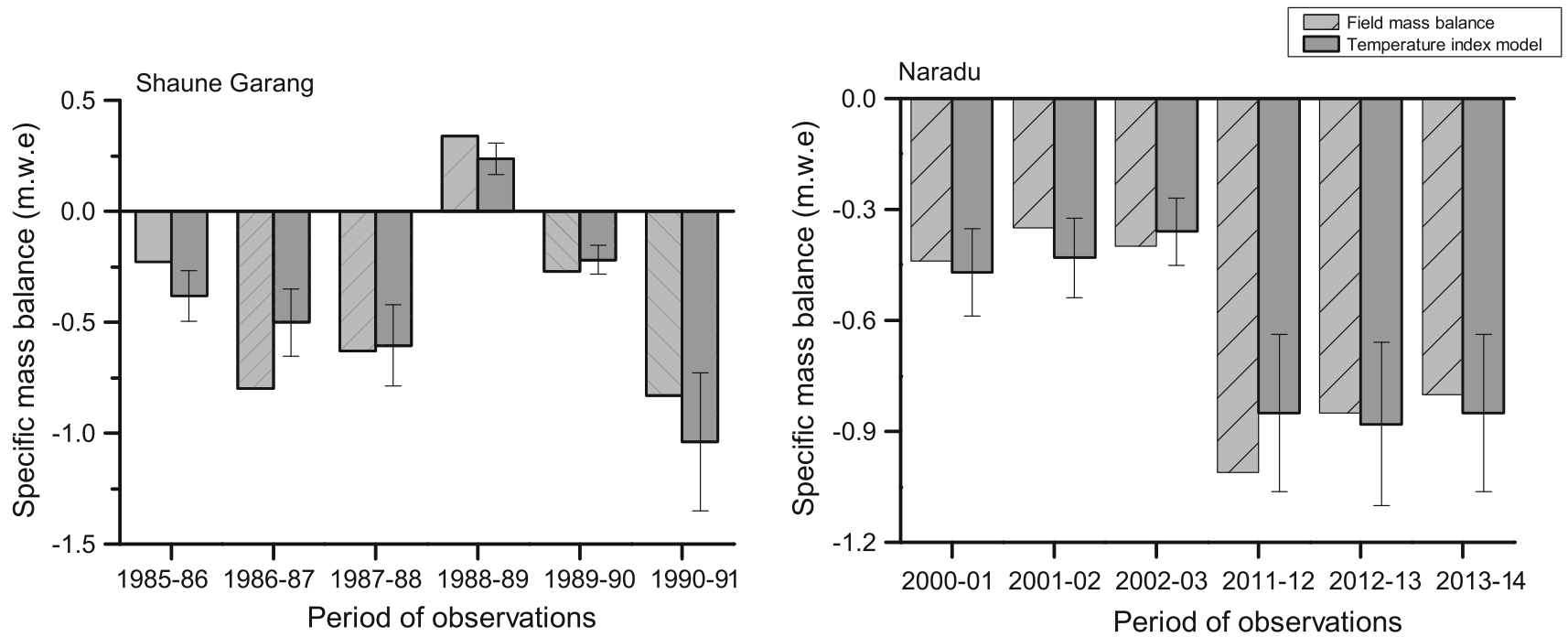

Figure 3. Comparison of mass balance from field and temperature index methods for Shaune Garang and Naradu glaciers between 1985-1986 and 2013-2014.

(a) Naradu
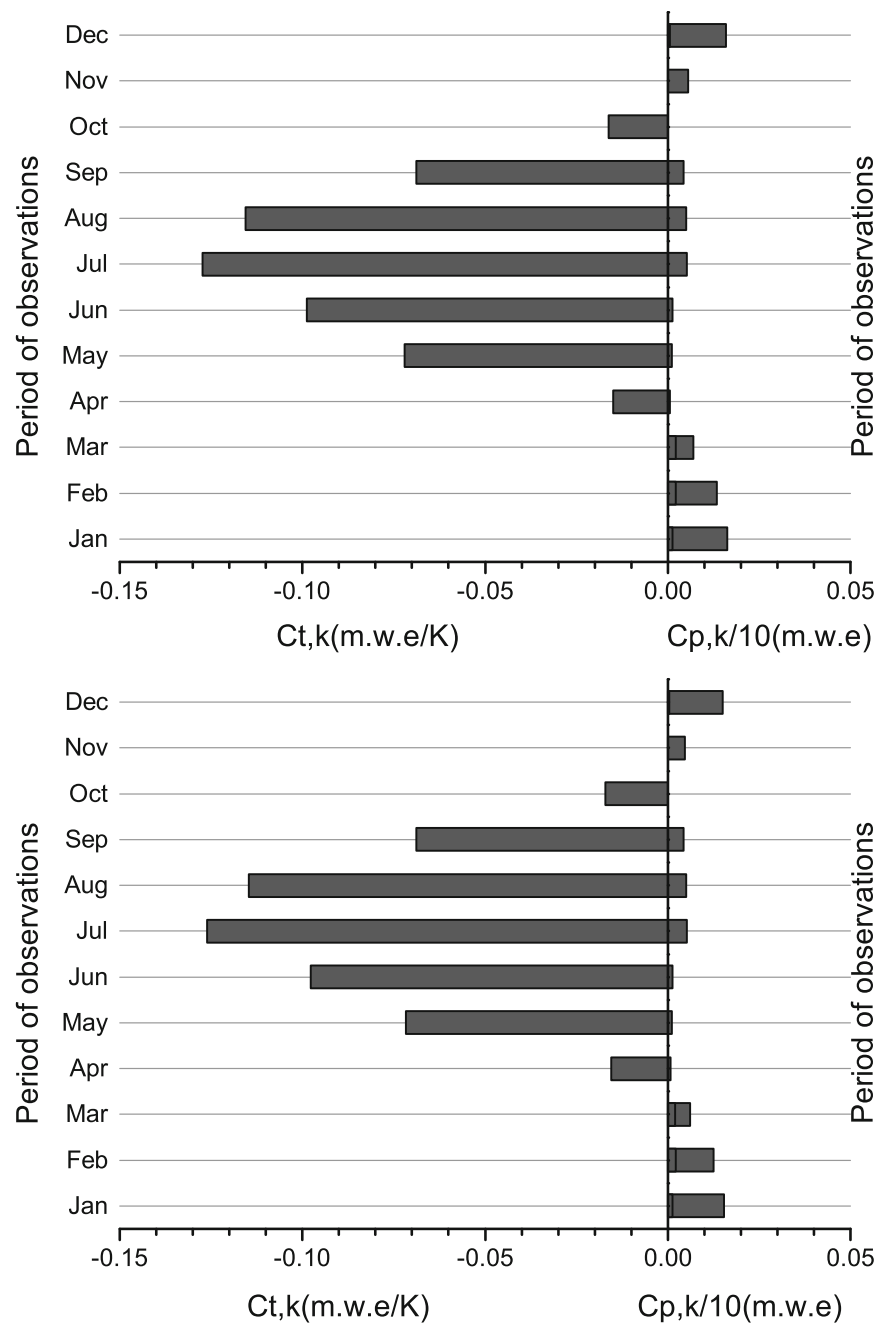

(c) Shaune Garang (b) Gara
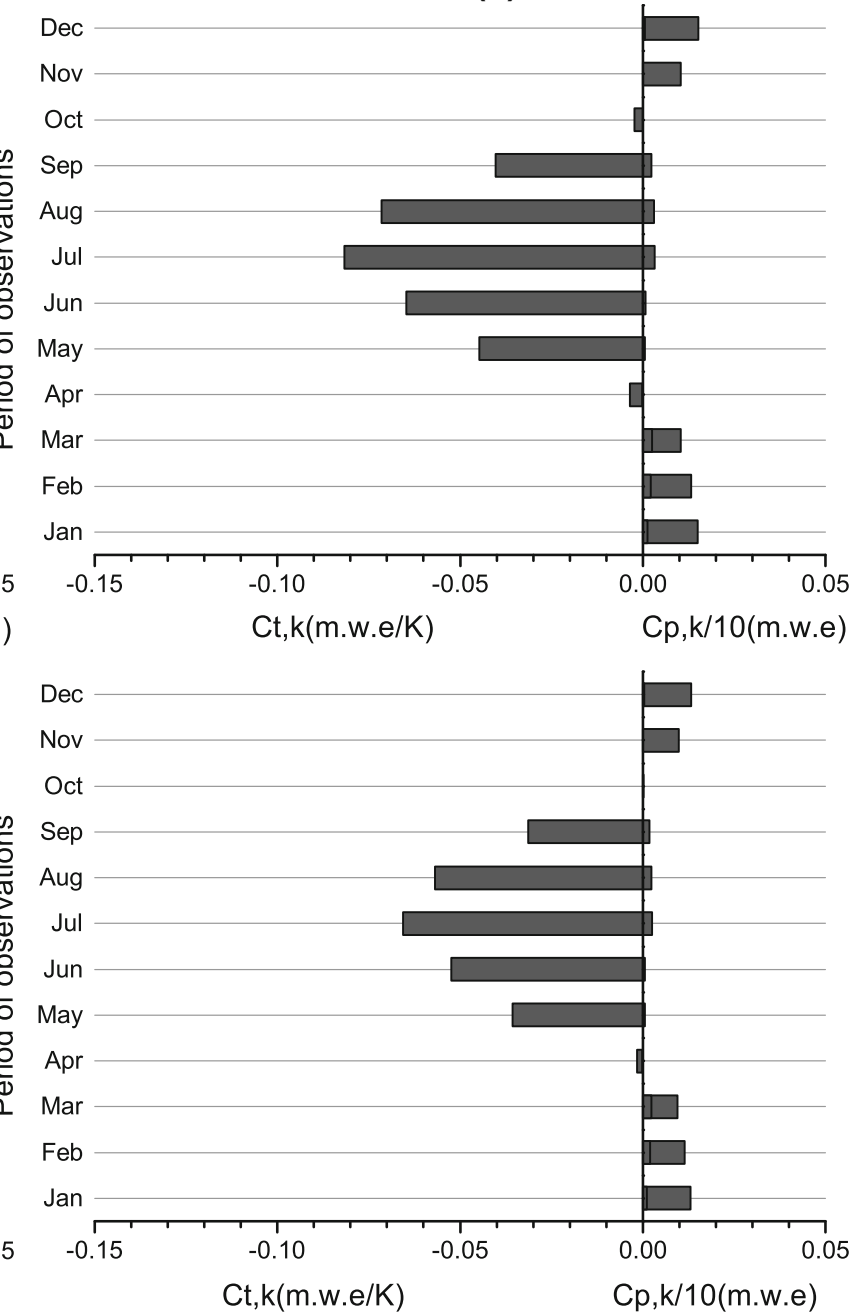

(d) Gor-Garang

Figure 4. Graphic representation of SSCs for four glaciers developed using meteorological data of Rakcham Observatory, between 1985-1986 and 2013-2014. 

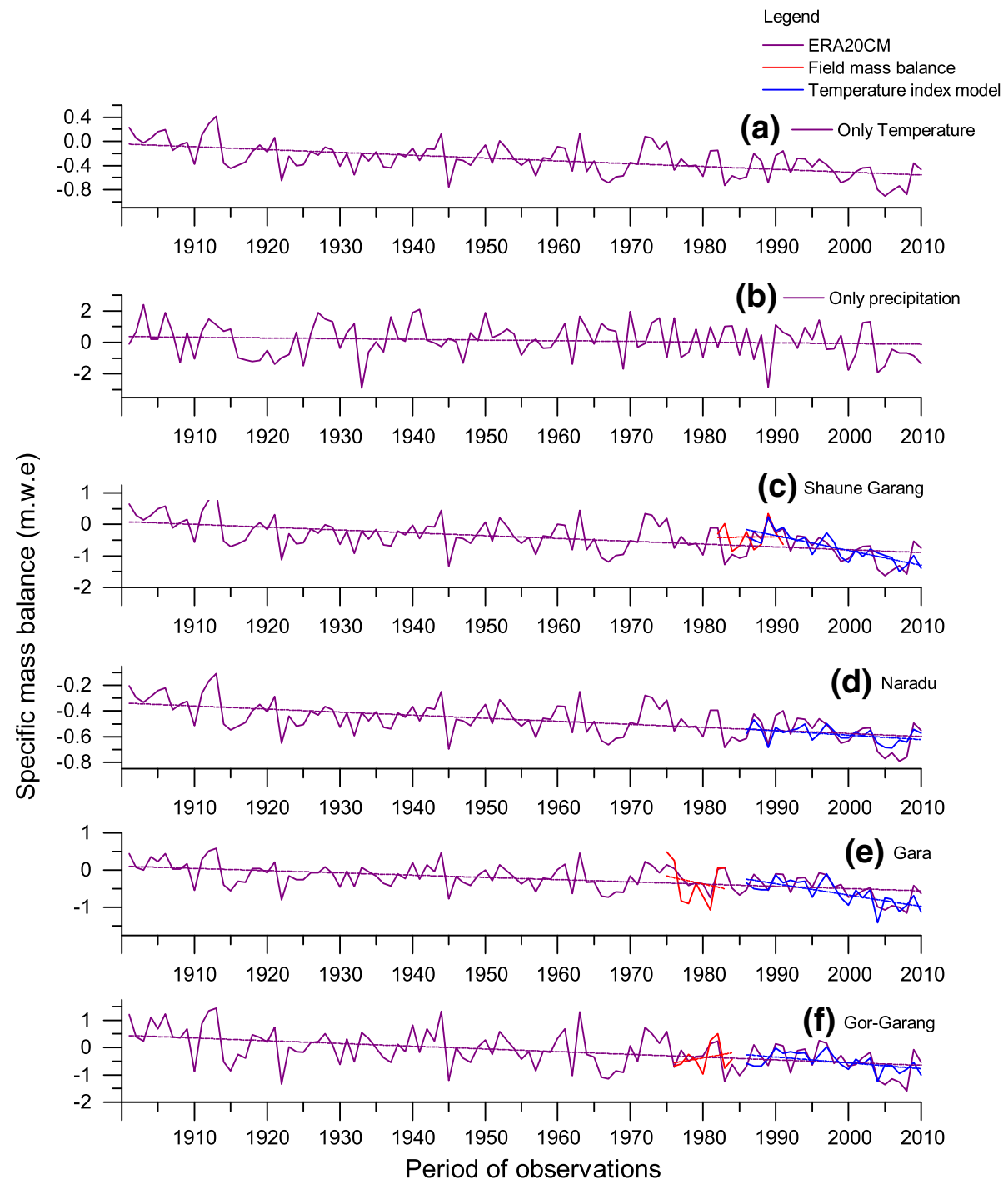

Figure 5. Calculation is for the present geometries of the glaciers. (a) Represents the influence of temperature only. (b) Shows the influence of precipitation and (c) shows specific mass balance derived using both temperature and precipitation anomalies for Shaune Garang. (d, e and f) Represent the specific mass balance of Naradu, Gara and Gor-Garang glaciers derived using ERA20CM, temperature index melt models and glaciological measurements for a period of 110 yrs, between 1900 and 2010.

season, westerlies have more contribution for solid precipitation and temperatures are well below the freezing point at glacier altitude. Whereas, temperature perturbations are higher than the normal during the ablation (May-October) season, which enhances the glaciers melt. Hence, precipitation perturbations are higher during accumulation season and temperature perturbations in ablation season, respectively.

\subsection{Mass balance observations and uncertainties during 1900-2010}

SSCs were forced with ERA-20CM ensemble climate reanalysis (temperature and precipitation) datasets of ECMWF centre (downloaded from http://apps.ecmwf.int/datasets/data/era20cm-ed $\mathrm{mo} /$ levtype $=\mathrm{sfc} /$ ) to reconstruct the specific mass balance (m.w.e) for a period of 110 yrs, as shown in figure $5(\mathrm{c}, \mathrm{d}, \mathrm{e}$ and $\mathrm{f})$. The details of the ERA-20CM ensemble datasets can be found in Hersbach et al. (2015). Precipitation and temperature measurements estimated using ERA20CM datasets and Rakcham Observatory are in good agreement with the recent meteorological observations, available in the same geographical region (figure 6; Shekhar et al. 2010; Davatlab and Wang 2015). The reconstructed specific mass balance measurements using SSC were correlated well with the field (shown with red colour in figure $5 \mathrm{c}$, e 

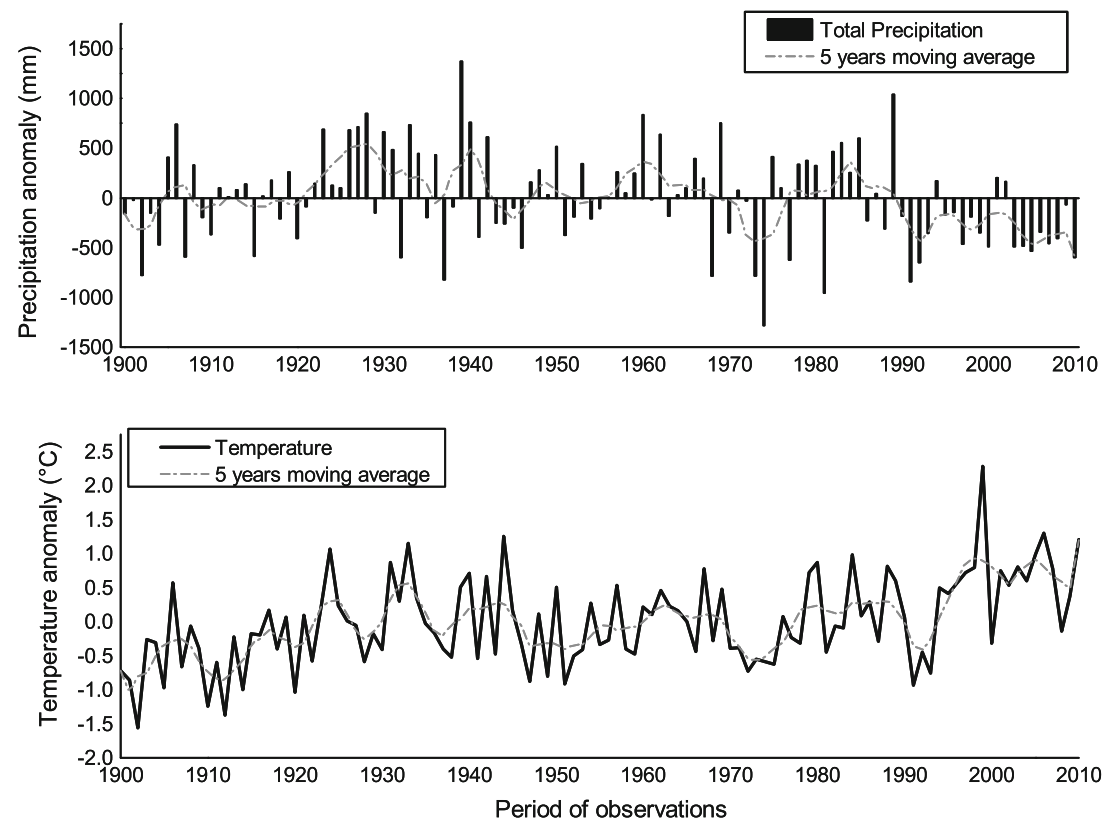

Figure 6. Precipitation and temperature anomalies derived using ERA 20CM datasets. Rapid changes in temperature and precipitation were observed after 1995.

and $\mathrm{f}$ ) and the modelled mass balance estimates using meteorological data from Rakcham Observatory (shown with orange colour in the same figures). The observations/analysis strongly suggest that the selected glaciers, except Naradu have experienced positive mass balance from 1900 to $1910 \mathrm{AD}$, and then negative mass balance after 1911 AD. Naradu glacier has experienced continuous negative mass balance from $1900 \mathrm{AD}$, because of its size, orientation and low-altitude location. High variations were observed in mass balance estimates for four glaciers and are $-0.2 \pm$ 0.44 to $-0.8 \pm 0.44$ m.w.e (Naradu), $0.7 \pm 0.41$ to $-1.1 \pm 0.41$ m.w.e (Gara), $0.8 \pm 0.54$ to $-0.9 \pm$ $0.54 \mathrm{~m} . w . e$ (Shaune Garang) and $1.5 \pm 0.6$ to $-1.6 \pm 0.6 \mathrm{~m}$.w.e (Gor-Garang), respectively. The mass balance pattern observed was declined during 1901-1920 and after 1940, with stable conditions during 1921-1940 AD. Mass balance was more negative after 1995, due to the snowfall deficiency and higher temperatures (figure 6) in this basin (Gaddam et al. 2016). In addition, other factors such as black carbon or mineral dust, emitted from forest fires has also shown severe effect on glaciers in this basin during the recent decade (Kulkarni et al. 2013).

\section{Conclusion}

An attempt was made in this study to evaluate the long term mass balance characteristics of four glaciers, in Western Himalaya using seasonal sensitivity characteristics (SSCs). The reconstructed mass balance correlated well with the field and remote sensing estimates and strongly suggests that the Gara, Shaune Garang and Gor-Garang glaciers have experienced both positive and negative mass balances, whereas Naradu has experienced only negative mass balance since 1900 AD. The observations also suggest that the glaciers in this region are losing mass in long term, with a higher rate after 1995. Since most of the glaciers in this basin are small in size valley glaciers $\left(<2 \mathrm{~km}^{2}\right)$, the basin may experience more mass loss in the coming decades and can cause a severe threat to the water supply for downstream communities. Hence, planning of mini or micro watershed management systems is necessary to avoid the critical scenario of water resources for Baspa basin in the near future.

\section{Acknowledgements}

Authors would like to thank Dr Ravichandran, Director, Dr Thamban Meloth (Project Head) and all Cryosphere team members, NCAOR for valuable support during the study. A special thanks to Editor, two anonymous reviewers and Prof. Helgi Bjornsson, University of Iceland for valuable discussions and suggestions during the study. Acknowledgements are due to BBMB and ECMWF for providing meteorological datasets of Rakcham 
Observatory and ERA20CM datasets. This work is a part of the $\mathrm{Ph} . \mathrm{D}$ programme registered under Visvesvaraya Technological University, Belgaum. The NCAOR Contribution number is 08/2017.

\section{References}

Adhikari S and Hybrechts P 2009 Numerical modeling of historical front variables and the 21st century evolution of glacier AX010, Nepal Himalaya; Ann. Glaciol. 50(52) $27-34$.

Azam M F, Wagnon P, Vincent C, Ramanathan A L, Favier V, Mandal A and Pottakkal J G 2014 Processes governing the mass balance of Chhota Shigri Glacier (Western Himalaya, India) assessed by point-scale surface energy balance measurements; The Cryosphere 8 21952217.

Bolch T et al. 2012 The state and fate of Himalayan Glaciers; Science 336 310-314.

Carenzo M, Pellicciotti F, Mabillard J, Reid T and Brock B W 2016 An enhanced temperature index model for debris covered glaciers accounting for thickness effect; Adv. Water. Res. 94 457-469.

Chai T and Draxler R R 2014 Root mean square error (RMSE) or mean absolute error (MAE)? Arguments against avoiding RMSE in the literature; Geosci. Model Dev. 7 1247-1250.

Davatlab R and Wang D 2015 Paleoprecipitation reconstruction in the Indus and Ganges basins by inverse modeling of tree ring based PDSI; J. Hydrometeorol. 161372 1386.

de Wildt M D R, Oerlemans J and Björnsson H 2003 A calibrated mass balance model for Vatnajökull, Iceland; Jökull No. 52 1-20.

Engelhardt M, Schuler T V and Andreassen L M 2015 Sensitivities of glacier mass balance and runoff to climate perturbations in Norway; Ann. Glaciol. 56(70) 79-88.

Gaddam V K, Kulkarni A V and Gupta A K 2016 Estimation of glacial retreat and mass loss in Baspa basin, Western Himalaya; Spat. Inform. Res. 24(3) 257-266.

Gardelle J, Berthier E, Arnaud Y and Kääb A 2013 Regionwide glacier mass balances over the Pamir-KarakoramHimalaya during 1999-2011; The Cryosphere $\mathbf{7}$ 1263-1286.

Geological Survey of India (GSI): Chapter 8, Annual Report 1991-1992, 175-176, 1992.

Hersbach H, Peubey C, Simmons A, Berrisford P, Poli P and Dee D 2015 ERA-20CM: A twentieth-century atmospheric model ensemble; Quart. J. Roy. Meterol. Soc. 1412350 2375 .

Hock R 2003 Temperature index melt modelling in mountain regions; J. Hydrol. 282(1-4) 104-115, doi: 10.1016/ S0022-1694(03)00257-9.

Hock R 2005 Glacier melt: A review on processes and their modelling; Progr. Phys. Geogr. 29(3) 362-391.

Huss M and Fischer M 2016 Sensitivity of very small glaciers in the Swiss Alps to future climate change; Front. Earth Sci. 4 34, doi: 10.3389/feart.2016.00034.
Immerzeel W W, Van Beek L P H and Bierkens M F P 2010 Climate change will affect the Asian water towers; Science 238 1382-1385.

IPCC 2014 Climate Change 2014: Impacts, adaptation, and vulnerability. Part A: Global and sectoral aspects; Contribution of working group II to the fifth assessment report of the Intergovernmental Panel on Climate Change; Cambridge University Press, United Kingdom and New York, NY, USA, 1132p.

Koul M N and Ganjoo R K 2010 Impact of inter- and intraannual variation in weather parameters on mass balance and equilibrium line altitude of Naradu glacier (Himachal Pradesh), NW Himalaya, India; Clim. Change, doi: 10. 1007/s10584-009-9660-9.

Kulkarni A V 2014 Glaciers as a source of water: The Himalaya; Pont. Acad. Sci. 41 1-6.

Kulkarni A V and Yogesh Karyakarte 2014 Observed changes in Himalaya glaciers; Curr. Sci. 106(2) 237244.

Kulkarni A V, Vinay Kumar G, Negi H S, Srinivasan J, and Satheesh S K 2013 The effect of black carbon on reflectance of snow in the accumulation area of glaciers in the Baspa basin, Himachal Pradesh, India; The Cryos. Disscuss. 7(2) 1359-1382.

Kulkarni A V Bahuguna I M, Rathore B P, Singh S K, Randhawa S S, Sood R K and Sunil Dhar 2007 Glacial retreat in Himalaya using Indian Remote Sensing Satellite data; Curr. Sci. 92(1) 69-74.

Kulkarni A V, Rathore B P and Alex S 2004 Monitoring of glacial mass balance in the Baspa basin using accumulation area ratio method; Curr. Sci. 86(1) 101106.

Kulkarni A V, Randhawa S S, Rathore B P, Bahuguna I M and Sood R K 2002 A snow and glacier melt runoff model to estimate hydropower potential; J. Indian Soc. Rem. Sens. 30(4) 221-228.

Maurer J M, Rupper B S and Schaefer M J 2016 Quantifying ice loss in the eastern Himalayas since 1974 using declassified spy satellite imagery; The Cryosphere 10 22032215 .

Oerlemans J and Reichert B K 2000 Relating glacier mass balance to meteorological data using a seasonal sensitivity characteristic (SSC); J. Glaciol. 46(152) 1-6.

Oerlemans J 2001 Glaciers and climate change; Balkema Publishers, Netherlands, 148p.

Paterson W S B 1998 The physics of glaciers; Pergamon Press, Birlington, MA, pp. 318-321.

Pellicciotti F, Helbing J, Rivera A, Favier V, Corripio J, Araos J, Sicard J E, and Carenzo M 2008 A study of the energy balance and melt regime on Juncal Norte glacier, semi-arid Andes of Central Chile, using melt models of different complexity; Hydrol. Process. 22 39803997.

Pratap B, Dobhal D P, Bhambri R, Manish Mehta and Vinod Chandra Tiwari 2016 Four decades of glacier mass balance observations in the Indian Himalaya; Reg. Environ. Chan. 16643.

Rabatel A, Letreguilly A, Dedieu J P, and Eckert N 2013 Changes in glacier equilibrium-line altitude in the western Alps from 1984 to 2010: Evaluation by remote sensing and modeling of the morpho-topographic and climate controls; The Cryosphere 7(5) 1455-1471. 
Raina V K and Srivastava D 2009 Inventory of the Himalayan Glaciers: A contribution to the International Hydrological Programme (Spec. Publ. No. 34); Geol. Surv. India 89 114-115.

Rathore B P, Kulkarni A V and Sherasia N K 2009 Understanding future changes in snow and glacier melt runoff due to global warming in Wangar Gad basin, India; Curr. Sci. 97(7) 10771081.

Sangewar C V and Siddique NS 2006 Thematic compilation of mass balance data on glaciers in Satluj catchment in Himachal Himalaya. Geol Surv India Report No. GL/NR/HQ/2006/01, 2p.

Shea M J, Moore R D and Stahl K 2009 Derivation of melt factors from glacier mass- balance records in western Canada; J. Glaciol. 55 123-130.
Shekhar M S, Chand H, Kumar S, Srinivasan K and Ganju A 2010 Climate-change studies in the western Himalaya; Ann. Glaciol. 51(54) 105-112

Singh P and Bengtsson L 2004 Hydrological sensitivity of a large Himalayan basin to climate change; Hydrol. Process. $182363-2385$.

Vincent C et al. 2013 Balanced conditions or slight mass gain of glaciers in the Lahaul and Spiti region (northern India, Himalaya) during the nineties preceded recent mass loss; The Cryosphere 7 569-582

Wulf H, Bookhagen B and Scherler D 2010 Seasonal precipitation gradients and their impact on erosion in the Northwest Himalaya; J. Geomorphol. 118 13-21.

Zhao L, Ding R and Moore C J 2016 The High Mountain Asia glacier contribution to sea-level rise from 2000 to 2050; Ann. Glaciol. 57(71) 223-231.

Corresponding editor: D SHANKAR 